\title{
Semiotics and Cartomancy: Tartu-Moscow Semiotic School Legacy
}

\author{
KOME - An International Journal of Pure \\ Communication Inquiry \\ Volume 3 Issue 2, p. 1-9. \\ (C) The Author(s) 2015 \\ Reprints and Permission: \\ kome@komejournal.com \\ Published by the Hungarian Communication \\ Studies Association \\ DOI: 10.17646/KOME.2015.21
}

\author{
Mattia Thibault \\ University of Turin, Italy
}

\begin{abstract}
This paper aims to reconstruct the fortune of the semiotic analysis of cartomancy, considered as a proper semiotic system, focusing in particular on the point of view of Tartu-Moscow School of Semiotics (TMS). TMS, founded by the renowned semiotician Yuri Lotman, offers one of the most interesting semiotic approaches to culture and communication yet is still partially ignored in the West with the exception, of course, of its founder.

Many TMS scholars approached cartomancy not only as an interesting cultural phenomenon but as a case study allowing them to test analytic tools that fit for many different forms of communication. Cartomancy is, at the same time, a quite simple semiotic system and a very sophisticated cultural phenomenon; this makes it a very useful object of study, allowing us to manipulate an entire (and rich) language while looking for the basic workings of all kinds of communication. The article will show how TMS analysis of cartomancy has already been quite productive and has had a few entails as well as how these analyses could help us to reach a better understanding of play, which is one of the biggest challenges that communication studies are facing today.
\end{abstract}

Keywords: Semiotics of Play, Semiotic Systems, Tartu-Moscow School of Semiotics, Cartomancy, Fortune telling 
"This process repeated itself more than a quarter of a century later with the founding of the Moscow-Tartu School of Semiotics. As if reproducing the structure of the first stage, the scholarly movement that sprang up formed at the intersection of two traditions: the Moscow Linguistic School and the Tartu Literary School, which was genetically linked to the Leningrad School of Formalism. The joint work of brilliant academics, such as the late M.I. Revzin and Ju.K. Lekomcev, and of an entire pleiade of scholars from Moscow, Tartu, and Leningrad (the circle later grew to include scholars from Erevan, Riga and other cities), as well as the work of philologists from abroad, determined the general contours of the scholarly movement. At first, their interest was focused on structure and on the language of the phenomena under investigation. During this period semiotic researchers went through a period of "spacial expansion." One after another, the most wildly different aspects of human activity — art, games, everyday behaviour, and so on-were described as languages."

Y. M. Lotman, The unpredictable workings of Culture p.51-52.

\section{Introduction}

Cartomancy has been a privileged object of study in Tartu-Moscow Semiotic School. Uspenskij and Lekomceva dedicate to it a speech (published in the proceedings in 1964) and an article (1965), and Egorov also wrote a paper on it (1965). Cartomancy, the form of divination exploiting playing cards, is a simple semiotic system that is highly schematized and relatively easy to reconstruct. For this reason, cartomancy has been considered not only a metaphor of natural language but also a similar modelling system of an inferior order of complexity. What started as almost a pretext - using cartomancy as a training object in order to pursue heuristic goals - later become the basis of several works fully dedicated to divination. Aphek and Tobin (1989) used this work as starting point for their fundamental book on semiotics of fortune telling that is still an unavoidable work of reference today. Also, Maria Corti (1973), in her semiotics analysis of Calvino's "Il Castello dei Destini Incrociati" (1969), retrieves a lot from the Tartu-Moscow works on cartomancy.

In this paper, we will illustrate the positions of the Tartu-Moscow scholars on cartomancy and show how their works have not only been useful in the past to other researches but can still provide solid tools of investigation to other branch of semiotics, in our case to semiotics of play. 


\section{Uspenskij and Lekomceva}

In the Moscow Symposium of 1962, B. Uspenskij and M. I. Lekomceva presented together an analysis entitled Cartomancy as a Semiotic System in which they approached fortune telling through cards as a proper language. This work was hence further developed in an article published in 1965 with the title "Describing a Semiotic System with a Simple Syntax."

The aim of Uspenskij and Lekomceva was to provide the description of a simple semiotic system in order to participate in the creation of a method of descriptive semiotics and to enhance the possibility of a comparison between natural languages and other semiotic systems. In the article, the authors implicitly admit that they have no true interest in the cultural phenomenon of cartomancy but that the semiotic analysis of cartomancy could have an heuristic value.

Uspenskij's and Lekomceva's approach to cartomancy is articulated in three steps, and to each step, they dedicate a paragraph: "Field data of cartomancy described in the metalanguage of linguistic terminology," "A semiotic description of cartomancy," and "The system of cartomancy compared to natural languages."

The first step, then, is the attempt to describe cartomancy using the metalanguage of linguistics. According to the authors, linguistics owns the more elaborated among the metalanguages of semiotic disciplines, making it the more suitable choice for any description of a semiotic system. According to linguistic terminology, then, cartomancy is indeed a language and is composed of two elements: a mechanism for the distribution of the cards, which generates sentences, and a vocabulary that explains the meaning of each card or idiomatic combination of cards. The authors proceed with the description of a popular method of fortune telling in which card distribution is articulated in two phases and determines the formation of nine sentences composed by a group of up to four cards. In addition, the distribution also determines attributes that contextualize each sentence (e.g., "What will happen" or "What you do not expect"). Uspenskij and Lekomceva also propose a table reporting the meaning that each card assumes in the act of fortune telling and showing how cards of the same suite and/or denomination often share semantic links. The main part of the analysis, however, is focused on the semiotic description of cartomancy and, in particular, in its pragmatics, semantics, and syntax.

Fortune telling always involves two people of differing status. The first one (A) is the fortune teller, and the second one (B) is the person whose future is being told. For A, if the signs on the cards only pertain to a code, B replaces the variable signifiers with specific meaning issued from his personal situation. In order to make cartomancy work, therefore, the meanings of the cards have to cover every possible life situation. In other words, according to a Saussurean conception of signs, A only has access to the signifier and the signified, while the referent is only accessible to B.

The distribution of cards in fortune telling determines that some sentences will focus on the past and the present of B. This step is the more delicate for A because he has to prove his abilities in a sort of test; B also knows the rules of cartomancy, the meanings of the cards, and, of course, his own past and present. Uspenskij and Lekomceva compare this situation to a game for two passive opponents in which all the moves are personal. The distribution makes it a game of chance (or alea, according to Caillois 1967), and systems of fortune telling that exploit all cards correspond to a game with complete information. Winning this game is the only way to keep the fortune telling from being a failure, thus A has to be able to interpret the reactions of B and, if possible, gather some information on 
him before the session. Winning the game, on the other hand, will also win B's confidence.

If telling the past and the present can be hard, according to the authors, telling the future is much simpler. B ignores his future as well, hence cartomancy becomes almost a selfgenerating system. The situation has already taken shape, and the fortune teller has much less freedom than before (he only needs to read the cards).

After the pragmatics, the authors analyse the semantics of cartomancy. Cards indicate both subjects (persons indicated by the faces) and predicates. The key planes used to interpret the meaning of the cards are simultaneously issued by the kind of situation manifested (usually marital or financial) and by the particular plane of each sentence ("What will happen," "What you do not expect," etc.).

Finally, the syntax of cartomancy is very simple because there is a high degree of freedom in the order of reading the signs, as often happens in simple languages with limited vocabulary. Even if it's not a rule, generally, the subjects are read first with the predicates read later.

The last paragraph of Uspenskij's and Lekomceva's article is devoted to comparing cartomancy to natural languages; the semiotic system of cartomancy can be considered a language with a finite number of states, limited semantics, and very simple syntax. Cartomancy share many features with natural languages; as in natural languages, preceding words and sentences influence the following. Additionally, different readings of the cards' meanings, which depend on the initially given situation, are analogous to variations of meaning depending on context in natural languages. Like natural languages, cartomantic systems are socially and ethnically conditioned.

\section{Egorov}

Boris Egorov's article on cartomancy was published in 1965 in the same issue of Sign System Studies than Uspenskij's and Lekomceva's, and is entitled The Simplest Semiotic Systems and the Typology of Plots. His approach, different from the previous, concentrates on cartomancy as a plot-generating mechanism.

The author acknowledges the work of Uspenskij and Lekomceva, but he's also critical. In particular, Egorov disagrees with the claim of the fortune teller (A) having a high degree of freedom while reading the cards. According to him, in professional fortune telling, A has an enormous advantage over his customer (B) that generally ignores the rules and meanings of cartomancy, and so A is granted an infinite amount of freedom. Cards, therefore, are pure fiction, and the game is played with the mind of B with his own expectations and reactions.

On the other hand, in honest fortune telling (as among friends) or when someone is telling their own fortune $(\mathrm{A}=\mathrm{B})$, the degree of freedom is very little if not non-existent. Honest fortune telling is the more interesting to Egorov because in that case, each card has an only meaning, which may vary only in strictly stipulated instances and which nuances are determined only in the context of the entire distribution.

In his article Egorov describes a different method of cartomancy which is similar, but different, from the one described by Uspenskij and Lekomceva. If the main features are still the same, both the distribution and the meaning of many cards are sensibly different. The most significant variation in the rules is a syntactical one: in this form of cartomancy the order of cards is fixed and meaningful and different sequences of the same cards have different meanings. 
Egorov, in the same way than Uspenskij and Lekomceva, is not particularly interested in the cultural phenomenon of cartomancy, but he prefers to focus on the way cartomancy is effective for generating plots. According to him, every reading of a series of sentences creates a new plot and the number of possible combinations of the 36 cards - and thus the number of possible plots - is immense: countless combinations can spring from a very little number of signs. This signs are particularly interesting to him because, when the author was writing, plot theorists were looking exactly for the "primary elements" of plot: "Obviously such a system is elaborated during a centuries-long developmental process in which the most significant and diverse actions and consequences are selected, and in this form it attracts our attention as a system of plots." (Egorov 1977: 77)

Egorov traces also a sort of history of plots, recalling that Vladimir Propp (1928) outlined thirty-one functions in fairy tales. Despite the possibility of reducing those functions in few smaller elements, not all their combinations would appear in fairy tales. Fairy tales are composed by functions that are, in fact, short plots: not every combination of the same elements fits. The increasing complexity of narrative through the centuries, however, brought to wider range of possible combinations of elements and thus to an increasing decomposition of this motifs in sub-motives. The number of elements increases proportionally to the number of ties between them, which in turn complicates the structure as a whole. It's impossible, therefore, to reduce all the different narrations to a small number of plots.

Even if cartomancy is extremely antique, contemporary cartomancy is a product of the modern era: the cards don't indicates short plots, but each one represents a single, indivisible element (a subject or a predicate). The method described by Egorov hosts twelve predicates, and the majority of them do not have a thymic value. Most of the predicates are identified by their value. When this happens, the suite introduces something qualitative, evaluative, or attributive to the meaning defined by it. Nonetheless, some of these elements still have an unspecified value depending on the context. Predicates such as "change" comprehend everything. These elements are not already part of the table of predicates, and their value is determined only by the context. Furthermore, Egorov also underlines that it is impossible to define a hierarchy of predicates by their meaningfulness, the latter depending on the interpretation given by the person whose future is being told (and thus variates according to the receiver and the context).

The author states that the sequence of subjects and predicates indicated by the cards can be easily represented with a formula (formed by the cards' conventional signs). Such a transcription of the plot would be objective and could be read by anybody. Unfortunately, according to Egorov, such a formula is still not possible with artistic works.

The article ends with a programmatic allegation from Egorov that a science of plots would be highly desirable. Such science, composed by a grammar, syntax, and history of plots, should create a complex table of all the possible elements pertaining to plots and investigate the ways they are interconnected. The analysis of cartomancy is then a model based on a simple system that should be applied with a higher degree of complexity to every form of narration.

\section{Influences and Entails}

The works of the Tartu-Moscow semioticians was, as we said, concentrated in using cartomancy as a model object of analysis in order to direct future academic efforts. However, these works have been among the basis of the monumental work from Edna Aphek and Yishai Tobin in Semiotics of Fortune Telling, published in 1989. Opposite to 
Egorov, Uspenskij, and Lekomceva, the main interest of this book is to actually shed light on the cultural relevance of fortune telling. In the fifth chapter, entitled "The Visual and the Textual in Cartomancy," Aphek and Tobin approach cartomancy as a complex, multilayer, semiotic system. It could be interesting quoting here the paragraphs in which they explain the differences of their approach from the previous works. The first paragraph underlines their divergences from Uspenskij and Lekomceva:

\begin{abstract}
We, on the other hand, believe that cartomancy represents a complex semiotic system where the meaning part of the card symbol functioning as a sign is oftentimes an index of exhaustive graded sometimes polysemic and "reversible" meanings which are part of a larger relative dynamic thematic continuum. The meanings of the cards may be seen as exhaustively classifying a larger thematic continuum if we view the "divinatory" meanings attached to each card as representing most, if not all, the possible semantic, cultural and social attributes of an umbrella term or theme related to that particular card. (Aphek and Tobin 1989: 138.)
\end{abstract}

The second one, on the other hand, is related to Egorov's work:

\begin{abstract}
We, on the other hand, have also included in our work, the notion of the separate and individual plot building of the members of the fortune-teller/client dyad and have extended the discourse plot to include both a visual semiotic system which revolves around the moment of reading: i.e. the line or direction followed by the eye in a particular spread, as well as a broader semiotic system of color, shape, form and number, since these elements of the various suits of the regular playing cards add to their meaning and interpretation. (Aphek and Tobin 1989: 138.)
\end{abstract}

As we can see, Aphek and Tobin don't completely reject the previous works, but they deepen and complicate their theories on the topic in the frame of a much wider study on all forms of fortune telling.

The work of Egorov Uspenskij and Lekomceva also influenced Maria Corti's "Le jeu comme génération du texte: Des tarots au récit," published in 1973. In this article, the Italian semiotician focuses on Italo Calvino's novel $\mathrm{Il}$ castello dei destini incrociati, published in 1969. In this novel, a series of characters tell their own stories using tarots as support. The cards are distributed according to rules similar to cartomancy, and the signs that they display are exploited in order to develop the plot. Corti refers several times to both theories (from Uspenskij and Lekomceva and from Egorov) that she uses to carry out her analysis. In particular, she focuses on the way in which Calvino is able to exploit the cards and their distribution in order to tell well-known stories, such as the one of Roland. Additionally, she shows the great awareness that Calvino had of the mechanics of plot generation by using a specific set of complex signs and their disposition.

Corti's article is an interesting way of retrieving useful and general concepts from the previous works on cartomancy and using them to shed some light on Calvino's way of thinking and writing.

What is still missing, however, is a semiotic analysis of cartomancy that takes into account the irrational and transcendent aspects that this practice may entail. Even if many scholars have already approached prophecy and divination from a semiotic perspective that also takes in account its sacred and transcendental aspects (see, for example, Volli 2011), such an approach has not yet been used to analyse cartomancy. The heritage of the strongly linguistic perspective adopted by Tartu-Moskow scholars has probably heavily influenced later semiotic works on the subject. Nevertheless, an extension of the analysis beyond this horizon would be, in fact, a new and interesting asset for understanding the 
phenomenon of cartomancy and its cultural relevance; therefore, in the author's opinion, it would be a desirable future addition to the theory.

\section{Cartomancy and Playfulness}

Even if Lotman did not write about cartomancy, in 1975, he wrote The Theme of Cards and Games in Russian Literature of the 19th Century (in Russian, meмa карm $u$ карточной игры в русской литературе начала XIX века, the translation I used was Lotman 1980), mainly focusing on Dame of Spades by Pushkin. In this work, Lotman stresses the fundamental duplicity of cards, being at the same time playful artefacts and instruments used for fortune telling. According to him, this duplicity becomes even more evident in literature, where games of cards often have the features of a struggle against destiny.

On the other hand, however, one can argue that the contrary is also true: every experience of cartomancy shows some feature that is properly game-like. As we have seen, Uspenskij and Lekomceva have compared fortune telling with a game between the fortune teller and his customer, a game in which the first player has to successfully interpret the reactions of his opponent in real time and act according to his interpretation, reconstructing the opponent's past and present life. However, the game-like features of cartomancy are not limited to the struggle between the people involved but run deeper in its mechanics.

The reflection of these mechanics can be seen, for example, in the order in which Lekomcheva and Uspenskij approach the three aspects of the semiotic system of cartomancy (pragmatics, semantics, and syntax). Natural languages are generally analysed in the opposite order: starting from syntax, going through semantics, and investigating the pragmatics only in the end. This epistemological reversal happens because, if natural languages are semiotic systems with a syntactical-semantical determination, cartomancy - this is what Uspenskij and Lekomceva appear to suggest - is a semiotic system that features a pragmatic determination. If this is true, it entails the subordination of the meaning and of the order of the signs to the rules that, in a very game-like way, regulate the disposition of the cards and the interactions between the people involved. Furthermore, considering cartomancy as a pragmatically determined semiotic system could also explain the relatively great amount of freedom and idiosyncrasy featured by cartomancy that is absent from less playful semiotic systems as natural languages.

Egorov, on the other hand, stresses the importance of fortune telling with cards as a way to create new plots through the recombination of a series of elements. Maria Corti echoes him, stating that tarots can be used to joindre et disjoindre les elements constitutifs d'une intrigue pour les transformer en matrices poetiques et ideologiques. [Join and separate the constituent parts of a plot, in order to transform them into poetic and ideological matrices.] (Corti 1973: 43)

This definition of cartomancy as a sort of matrix of plots and is very close to Ferri's definition of games that he considers an interactive matrix that actualizes the elements of the game's repertory into a single narration (or game-text) (Ferri 2007). Thus, games feature both a repertory and a set of rules that mixes and brings together the repertory's elements. These components are the same that Uspenskij and Lekomceva indicate as constituting cartomancy: a vocabulary and a system of distribution. Additionally, if cards change meaning according to the ones that form the same sentence in cartomancy, in many games, the value of the cards depends fully on the combinations they makes with the others. 
However, while the interactive matrix of games is, by definition, interactive, the distribution of the cards is determined only by randomness and by the rules without any decision made by the players involved. The choice of the reading order, nevertheless, can be considered a part of a playful behaviour, and it works like a sort of puzzle that the fortune teller has to solve. A cartomancy session, from this perspective, is not very different from a solitaire: the player has to find a new order to randomly distributed cards.

Finally, we can say that cartomancy is characterized by rules, a certain amount of creativity and make believe, and even a dose of risk, which are all elements typical of games.

On the other hand, cartomancy is not always perceived as game-like because it can be taken very seriously. Lotman describes play as a twofold activity: the player is simultaneously following a conventional (thus fictional) behaviour and a practical one (Lotman 2011). The player acts as the world of play were real, and at the same time, he knows it is not. Also, Caillois (1967) states that one of the characteristics of play is that it has to be conscious of its own fictionality. It follows that, if the fortune teller does truly believe in what he's doing, he is not playing, thus cartomancy, for him, is no game. However, if the fortune teller's faith in his ability to tell the future it is not so strong or, more likely, if cartomancy is either a profession or a hobby for him, we could harmlessly define fortune telling with cards being a game. Either way, the relationship between games and cartomancy shouldn't be surprising. According to Lotman, play often models the randomness of our world (2011: 256). Henceforth, if we believe that the apparently random events of life are, in fact, already written and predetermined, play becomes a model of fate itself.

\section{References}

Aphek, E. and Tobin, Y (1989) Semiotics of Fortune Telling. Amsterdam and Philadelphia: John Benjamins.

Caillois, R. (1967) Les Jeux et les homes. Paris: Gallimard.

Calvino, I. (1969) Il castello dei destini incrociati. In Italo Calvino and S. Samek Ludovici Tarocchi: il mazzo visconteo di Bergamo e New York. Parma: Franco Maria Ricci.

Corti, M. (1973) Le jeu comme généation du texte: Des tarots au récit. Semiotica 7(1), 33-48.

Egorov, B. (1965). Prosteyshiye semioticheskiye sistemy i tipologiya syuzhetov. Sign Systems Studies 2, II: 106-115. Translation: Egorov, B. 1977. The Simplest Semiotic Systems and the Typology of Plots. In Soviet Semiotics: An Anthology, edited by Daniel Lucid, 77-86. Baltimore: Johns Hopkins University Press.

Ferri, G. (2007) Narrating machines and interactive matrices. A semiotic common ground for game studies. In Situated Play. Proceedings of DIGRA 2007 Conference, 466-473.

Lekomceva, M. I., and Uspenskij, B. A. (1962) Cadanie na igralnikh kartakh kak semioticheskaya sistema. Simpozium, 83-86.

Lekomceva, M. I., and Uspenskij, B. A. (1965). Opisaniya odnoy semioticheskoy sistemy s prostym sintaksisom. Sign System Studies 2, II: 94-105. Translation: Lekomceva, M. I., and B. A. Uspenskij. 1977. Describing a Semiotic System with a Simple Syntax. In Soviet Semiotics: An Anthology, edited by Daniel Lucid, 65-76. Baltimore: Johns Hopkins University Press. 
Lotman, Y. M. (1980) "Il tema delle carte e del gioco nella letteratura russa dell'inizio del secolo XIX." In Salvestroni, S. (ed.), Testo e contesto. Semiotica dell'arte e della cultura, 151-190. Roma-Bari: Laterza.

Lotman, Y. M. (2011) The place of art among other modelling systems. Sign Systems Studies 39(2/4), 251-270.

Lotman, Y. M. (2013) The unpredictable workings of Culture. Tallin: TLU Press.

Propp, V. (1928) Morfologiija skazki. Leningrad: Akademia.

Volli, U. (2011) "Previsione, profezia, senso". in De Maria Gian Marco (ed.) Ieri,oggi, domani - Studi sulla previsione nelle scienze umane. 19-36. Roma: Aracne Editrice. 